\title{
Pandemia en el siglo XXI. Reflexiones de la(s) geografía(s) para su comprensión y enseñanza
}

\author{
María Cristina Nin \\ @ [ninmcristina@gmail.com ] \\ Melina Ivana Acosta \\ @ [ meliacosta24@gmail.com ] \\ Stella Maris Leduc \\ @ [ leduc.stellamaris@gmail.com ] \\ Universidad Nacional de La Pampa ${ }^{1}$
}

DOI: http://dx.doi.org/10.19137/huellas-2020-2412

\section{Introducción}

"Una pandemia de esta dimensión causa justificada conmoción en todo el mundo. Aunque el drama está justificado, es bueno tener en cuenta las sombras que crea la visibilidad" (Boaventura de Sousa Santos, 2020).

Las enfermedades consideradas como endemias, epidemias o pandemias tienen una estricta relación con las Ciencias Sociales, especialmente con la Geografía ya que se definen por el ámbito geográfico de su expansión. Epidemia es una enfermedad "que se propaga durante algún tiempo por un país, acometiendo simultáneamente a gran número de personas" (RAE, 2020). La epidemia del ébola ocurrida en África Occidental en 2014 colapsó el sistema de salud de Sierra Leona, Liberia y Guinea. Actualmente en República Democrática del Congo hay un brote de Sarampión que registra al mes de marzo 6000 personas fallecidas (MSF, 2020). Las enfermedades endémicas son las que persisten en un área específica de forma continua o

1 Docentes e investigadoras del Instituto de Geografía de la Universidad Nacional de La Pampa. Este trabajo se enmarca en el Proyecto de Investigación "Geografía y enseñanza (De) construyendo teorías, prácticas, contextos y sujetos". Aprobado por Resolución 042-18-CD-FCHUNLPam. 
con episodios. Malaria, chagas, dengue, tuberculosis, fiebre hemorrágica argentina, entre otras. En cuanto a pandemia, el origen griego de la palabra “ $\pi \alpha v \delta \eta \mu i ́ \alpha$ pandēmía 'reunión del pueblo"'(RAE, 2020), representa claramente la realidad que la sociedad global atraviesa desde noviembre de 2019, fecha de aparición del coronavirus COVID-19. El virus detectado en Wuhan, ciudad China, se expandió al ritmo de las comunicaciones del siglo XXI, hacia otros países de Asia, luego Europa, Oceanía, América y África, motivo por lo cual fue declarado pandemia por la Organización Mundial de la Salud (OMS) el 11 de marzo de 2020²(ONU, 2020a). Esta organización considera pandemia a una enfermedad que se propaga mundialmente.

Según Enrique Dussel (2020a) es la primera vez en la historia de la humanidad que se vive simultáneamente en tiempo real un proceso acelerado que va a llevar a revisar el sistema, es decir repensar los objetivos de la humanidad. La sociedad tiene la oportunidad que esta pandemia nos otorga, en relación al origen de su significado, la de reunirnos a pensar cómo enfrentarla y luego planificar estrategias para superar los impactos territoriales.

Diversos actores sociales debaten, intercambian ideas, posicionamientos y puntos de vista respecto al Coronavirus como pandemia global. $\mathrm{La}$ comunidad educativa, colegas, formadores, estudiantes, médicos, científicos, académicos de diversas disciplinas, la sociedad civil, gobiernos, el Estado, entre los que se podrían mencionar, reflexionan acerca de las consecuencias multivariables a escala global, regional y local. Alba Rico y Herrero (2020, p. 2), deliberan acerca de cuestiones filosóficas,

lo que estamos viviendo no es una guerra, es una catástrofe. En una catástrofe puede ser necesario movilizar todos los recursos disponibles para proteger a la sociedad civil, incluidos los equipos y la experiencia del Ejército, pero el hecho de que una catástrofe exija tomar medidas de excepción, no autoriza sin peligro a emplear una metáfora que, como todas las metáforas, transforma la sensibilidad de los oyentes y moldea la recepción misma de los mensajes.

Este contexto complejo, incierto e inédito nos interpela como investigadoras/es y docentes acerca del rol de ocupa que la Geografía, tanto para intervenir en la problemática, y a su vez para brindar marcos teóricos y herramientas para su enseñanza en los diferentes niveles educativos. La Geografía como ciencia social, analiza las relaciones territoriales en sus

2 En la actualidad existen otras pandemias que persisten desde hace décadas, sin embargo la rápida propagación del Covid-19 es la que la convierte en peligrosamente diferente al resto de las existentes. Por su expansión geográfica la influenza y el VIH son consideradas enfermedades pandémicas. 
diferentes dimensiones, social, ambiental, cultural, económica, geopolítica, histórica, sanitaria, educativa, y las complejidades y transformaciones que resultan de su interrelación. Es decir, resulta una ciencia clave para comprender este fenómeno humanitario de escala global.

Es una disciplina privilegiada para indagar, analizar, comprender e interpretar esta problemática que afecta a las poblaciones de todo el mundo. Si bien es un problema que se expandió por todo el globo, sin embargo sus consecuencias no serán homogéneas y, de acuerdo a la gestión y las acciones que desarrollen los Estados para paliar la enfermedad, dependerá el mayor o menor grado de desigualdad que sufran las sociedades. En este sentido, Harari (2020) expresa que a "largo plazo, la peor de las crisis se sufrirá en los países más pobres". Es precisamente en estas premisas que tenemos que poner el foco de análisis, porque si bien el debate actual gira entorno a la realidad de España e Italia, a las decisiones desacertadas del Reino Unido y EEUU, a la gestión de la expansión de la enfermedad de China, Corea del Sur o Singapur, las consecuencias más trágicas se observarán en las poblaciones más vulnerables. Estados débiles, con sistemas e instituciones sanitarias precarias, poblaciones rurales que tienen poco o nulo acceso a vías de comunicación para llegar a un hospital, campamentos de refugiados donde prima el hacinamiento y falta de recursos vitales como el agua, zonas afectadas por conflictos armados, ciudades con millones de habitantes sin agua potable ni sanitarios, sin viviendas dignas, niños sin protección familiar, sin escolaridad, mujeres bajo estado de violencia, adultos mayores sin amparo, es decir, geografías inexploradas para gran parte de la ciudadanía mundial. Con el propósito de superar el desconocimiento de los territorios ignorados ${ }^{3}$, la Geografía como ciencia debe bucear en conceptos construidos, resignificarlos y construir nuevos en relación con las demandas explicativas que nos atraviesan en el momento actual.

La Geografía, además de otras como la Historia, la Sociología, la Filosofía, la Antropología, la Construcción de la Ciudadanía, como disciplina escolar resulta relevante. Su enseñanza en las instituciones educativas no sólo destaca por la significatividad de la temática, sino además, por la complejidad que requiere su análisis desde múltiples perspectivas. Este punto resulta central para nuestro campo de acción, tanto en la formación

3 Lois (2018) dice, “(...) las terrae incognitae designan tanto lo que se conoce como lo ignorado, lo inexplorado, lo supuesto, lo mal conocido, lo plausible, lo verosímil, lo increíble, lo esperado, lo deseado, lo buscado, lo que está más allá del horizonte (el plus ultra), lo otro, lo diferente, lo proyectado, lo anticipado, lo inconsciente, lo extranjero, la exterioridad" (p. 23). En este trabajo interpretamos que la visibilidad de territorios y poblaciones ignoradas a partir de las consecuencias de la Pandemia, es una oportunidad para las Ciencias Sociales y de la Geografía para producir conocimiento y superar el desconocimiento de "geografías ignoradas". 
universitaria como así también, como docentes en escuelas secundarias. La tecnología resulta, en este sentido, una herramienta poderosa para acercar y garantizar la continuidad pedagógica de los y las estudiantes que, por razones de prevención deben permanecer en sus hogares. Los docentes, equipos de gestión, coordinadores, técnicos asesores del Ministerio de Educación, personal administrativo, entre otros, trabajan para brindar la enseñanza de las disciplinas a través de diversos dispositivos y soportes tecnológicos. El COVID-19 colocó en evidencia las desigualdades sociales globales y la brecha generacional respecto al uso de la tecnología para innovar en la enseñanza, donde conviven propuestas innovadoras con las más tradicionales.

A partir de interpretar el escenario mundial actual es que nos proponemos delinear en este artículo algunas reflexiones para seguir pensando en el marco de la multiperspectividad de la Geografía para su enseñanza en el aula.

\section{Geografía, aportes teóricos y metodológicos para comprender la pandemia}

El lingüista y politólogo Noam Chomsky (2020) reflexiona acerca de que los niños no son recipientes, y afirma que este "es el momento de enseñarles a entender el mundo". Es el momento de darles oportunidades para que sigan su instinto creativo, para que exploren el mundo todo lo que puedan. En este sentido la Geografía se propone enseñar a comprender el mundo desde hace décadas y siempre ha significado un desafío andamiar y construir saberes que posibiliten la interpretación de la compleja realidad.

La emergencia nos interpela y al mismo tiempo nos pone en acción debido a que confluyen en su estudio los paradigmas de la Geografía que invitan a comprender la problemática desde las múltiples escalas de análisis con los aportes de la geopolítica ${ }^{4}$, la geografía de la salud, la geografía económica, la geografía de la percepción y el comportamiento, la cuantificación de los datos, las geotecnologías y la construcción de cartografías 5 .

4 Desde una mirada geopolítica, Harvey (2020) aborda la política anticapitalista en la época del COVID-19 y señala "cuarenta años de neoliberalismo han dejado lo público totalmente expuesto y mal preparado para enfrentar una crisis de salud pública en la escala del coronavirus"; Silvia Marcú (2020) analiza el rol de la Unión Europea frente a la crisis sanitaria ocurridas e Italia y España; Méndez (2020) reflexiona sobre la crisis del COVID-19: sitiados por el Coronavirus: consideraciones de un geógrafo; Schulz (2020) analiza sobre la geopolítica del COVID-19.

5 Acerca de las cartografías de Aeroterra "Casos Globales" de COVID-19 que se actualiza en tiempo real, Recuperado de: https://aeroterra.maps.arcgis.com/apps/opsdashboard/index.html 
Estas geografía(s) nos interpelan y hacen flaquear las respuestas unilaterales acerca de la situación. En este sentido, se requiere de un trabajo interdisciplinario para profundizar lecturas y análisis con el propósito de lograr una interpretación más acabada del fenómeno humanitario en curso.

Asimismo, se desarrollaron diferentes mecanismos por parte de los Estados para prevenir y proteger a las personas, así como informar sobre el desarrollo del proceso, aunque por estos días, se conocen que varían constantemente las cifras oficiales de infectados, no conociendo si realmente es el número real de personas que poseen el virus. Si bien atender la salud pública es primordial en este momento, acompañar el proceso de enseñanza y aprendizaje en las instituciones educativas representa una preocupación y un desafío pedagógico.

Entendemos que las producciones y la bibliografía académica es incipiente por la reciente Pandemia, ya existen en la web numerosos escritos de autores reconocidos que invitan a pensar y problematizar acerca de diversas teorías y puntos de vista. En este sentido, nuestro aporte contribuiría a delinear en clave Geográfica y educativa el contexto incierto y desafiante que nos interpela.

Los medios de comunicación ${ }^{6}$ realizan diversos análisis acerca de la Pandemia, los noticieros y periódicos permanentemente en diferentes bandas horarias hacen circular noticias de variado tenor, donde participan analistas y especialistas en materia de salud y también economistas quienes efectúan pronósticos acerca de las repercusiones económicas ${ }^{7}$ y sociales ${ }^{8}$, tanto de nuestro país, como en el mundo?.

\#/6c7f6816cdb84c4498c8423cbc5686a5, También la realizada por la Infraestructura de Datos Espaciales (IDE) del Instituto de Geografía de la Facultad de Ciencias Humanas - UNLPam. Mapa de los casos de corona virus de Argentina: elaboración Bossa, Juan Pablo (2020), en base a los reportes diarios del Ministerio de Educación de Salud. Argentina. Presidencia de la Nación. Recuperado de: https://sites.google.com/humanas.unlpam.edu.ar/ideigunlpam/ $\mathrm{p} \% \mathrm{C} 3 \%$ A1 gina-principal?authuser $=2$

6 Al respecto Tobío (2020) analiza criticamente el rol de los medios de comunicación y la pandemia. Por su parte, Lois González (2020) reflexiona sobre la geografía periodísca de la crisis del coronavirus.

7 Entre las consecuencias económicas de la pandemia, la actividad turística es abordada con especial preocupación en publicaciones como las de Dillon (2020); Fletcher y otros (2020) en las que se analizan el decrecimiento de la actividad turística en relación con la crisis del COVID-19.

8 Periodistas, sociólogos economistas y filósofos publican sus interpretaciones y debates acerca del origen y consecuencias de la Pandemia, entre ellos se pueden sugerir: Zizek, (2020), Agamben (2020), Han (2020), entre otros.

9 Se pueden consultar los debates escritos por académicos del mundo y Argentina en la siguiente compilación: La Fiebre (2020) Svampa y otros. 
El virus surge en la ciudad de Wuhan (con aproximadamente 12 millones de habitantes) en diciembre de 2019 como epicentro del coronavirus en China. Con gran velocidad migró a países europeos como Italia y España, luego hacia Irán, Japón, Corea del Sur, Estados Unidos. El crecimiento comienza a ser exponencial en diversos países del globo. En la primera quincena de abril son pocos los países que no posean entre su población contagiados.

En China comenzaron rápidamente a tomar medidas ante la emergencia sanitaria tales como la restricción severa de movimientos, confinamientos, cuarentena, cierre temporario de fábricas y reanudación organizada de la producción, cierre de aeropuertos, control de casos y tratamientos especializados. En diez días en China construyeron un hospital para alojar a las personas infectadas y pudieron controlarlo, sin embargo, la enfermedad se trasladó hacia otros países y regiones. Así lo expresan expertos de la OMS,

La unánime conclusión del equipo es que China ha cambiado el curso del brote dentro del país. Lo que era un brote de rápido crecimiento, se estabilizó y ha comenzado a bajar más rápido que lo que uno puede esperar si hubiéramos estado mirando a las dinámicas naturales de este tipo de casos (ONU, 2020 b).

Las infraestructuras sanitarias en América Latina y en Argentina en particular, reflejan el escaso desarrollo en la atención integral de la salud. Se profundizan también las desigualdades, la pobreza, la marginación, la exclusión, ${ }^{10}$ dado que son "(...) las deficiencias en saneamiento, vivienda y otros factores que dan forma a los resultados de salud" (ONU, $2020 \mathrm{c}$ ). Si bien se han realizado inversiones en insumos y material descartable para acompañar el proceso de vigilancia epidemiológica, no son las suficientes para acompañar un contagio masivo de la población. Por ello, en el caso de Argentina, se intensifican las medidas de prevención por parte del Estado nacional referidas al aislamiento social, preventivo y obligatorio (ASPO) para preservar la salud pública y evitar la propagación de los contagios. No obstante las desigualdades que Argentina tiene respecto a países del norte, Científicos del Servicio de Virosis Respiratorias del ANLIS Malbrán, lograron en la primera semana de marzo secuenciar el genoma completo

10 Acerca de la Pandemia y la exclusión se sugiere las reflexiones de: Julian Mora Aliseda (2020) Pandemia, Pobreza y Población (P.P.P.) Una Espiral Viral; Vicente Rodríguez Rodríguez. (2020) COVID-19 y Las Personas (Mayores) En El Análisis Geo-Demográfico (I) y COVID19 y Las Personas (Mayores): Los Entornos Geográficos y Sociales (II). Por su parte María Eugenia Prieto Flores (2020) analiza el uso de los espacios en adultos mayores. 
SARS COV-2 a partir de muestras de tres pacientes argentinos. Este avance científico posiciona al país en el mapa mundial ${ }^{11}$ ya que permite saber cuáles son las cepas que hoy afectan a la población (Argentina.gob.ar, 2020).

El Estado argentino cumple un rol destacado, que se ha reconfigurado. En este sentido, recuperamos las palabras de Kliksberg cuando expresa que,

El Estado reaparece en este nuevo contexto político como un actor imprescindible para promover e impulsar cambios en los rumbos deseados. ¿Pero se halla en condiciones de hacerlo? Existe un vasto consenso en que se requiere para ello un rediseńo integral que siente las bases de un Estado de nuevo cuño. El mandato emergente va en la dirección de un estado activo, pero asociado estrechamente con la sociedad civil y potenciador de la acción productiva de las empresas, fuertemente centrado en lo social, descentralizado, con gran parte de su acción desarrollada a nivel regional y local, totalmente transparente, rendidor de cuentas y sujeto de control social, de alta eficiencia gerencial, y apoyado en un servicio civil profesionalizado basado en el mérito. Asimismo, se aspira que sea un estado abierto a canales continuos de participación ciudadana" (Kliksberg, 2005, p. 18).

\section{El contexto educativo. Desafíos para la enseñanza en tiempos de pandemia}

En el ámbito educativo, las instituciones integradas por sujetos, que actúan y deciden en función de sus miradas éticas y políticas respecto a la crisis global, que se convierte en local cuando se aproxima y afecta las relaciones cotidianas, se ven interpeladas y obligadas a repensar la formación de los/as estudiantes. Comprender que cada actor institucional, en tanto ciudadano/a con derechos y responsabilidades como integrante de la sociedad, necesita fortalecer el trabajo colaborativo a través de las redes para atender las desigualdades con finalidad pedagógica.

La escuela como institución que atiende a niños/as, jóvenes y adolescentes, considerados por los organismos de salud como población de menor riesgo, se encuentra con diversas situaciones vinculadas con la vulnerabili-

11 Existe una Plataforma Científica Mundial denominada "Global Initiative on Sharing All Influenza Data (GISAD)" en la cual los avances respecto al SARS-COV 2 se comparten en tiempo real, los países están interconectados y socializan sus investigaciones, de este modo los descubrimientos aceleran la posibilidad de mejorar la calidad de diagnóstico, complementar la vigilancia epidemiológica y contribuir al desarrollo de una fórmula vacunal representativa de las cepas circulantes en el país y en la región (Argentina.gob.ar, 2020). La GISAD se puede consultar en el siguiente enlace: https://www.gisaid.org/. 
dad social, económica, tecnológica que requiere de decisiones prioritarias en relación con esas necesidades.

Asimismo el COVID-19 pone en evidencia la vulnerabilidad de los/as docentes frente al uso de la tecnología como herramienta para enriquecer la enseñanza. La situación de aislamiento social y preventivo declarado por el Estado desde el 16 de marzo con mayor intensificación a partir del 20 de marzo, incentivó la puesta en marcha de diferentes formas y modos de acceso a las tecnologías para propiciar la continuidad de los procesos de enseñanza y de aprendizajes de los y las estudiantes en los diferentes niveles educativos.

En Argentina, el Estado a través del Ministerio de Educación, despliega diferentes estrategias para acompañar el proceso pedagógico de los y las estudiantes mediante materiales destinados a la enseñanza y los aprendizajes en el marco del Programa nacional Seguimos Educando ${ }^{12}$ y el Programa provincial Estudiar Cuidándonos ${ }^{13}$, que organizan una propuesta de acompañamiento a las iniciativas de jurisdicciones, escuelas y educadores, con audiovisuales, programas de TV y radio, entre otros. Para todos los actores institucionales ha significado un desafío llegar con las diferentes propuestas a todos los territorios urbanos, rurales, con acceso a internet o sin acceso, con computadoras o celulares.

Las plataformas virtuales, surgieron o (re)surgieron como novedosas ante esta situación de aislamiento social. Se modifica la noción de escala, el espacio ahora cotidiano, doméstico, simbólico, un rincón de nuestros hogares se convierte en lugar de encuentro virtual, se abren ventanas que nos conectan con las instituciones educativas de los diferentes niveles del sistema educativo.

Para analizar este contexto, los conceptos acuñados por Lander (2000) acerca de la Colonialidad del saber y por Quijano (2014) sobre la Colonialidad del poder, que se evidencian a partir de un nuevo colonialismo global, favorecen las interpretaciones en relación con los intereses e intencionalidades de los actores. Entre ellos, las empresas tecnológicas que ofrecen diferentes tipos de softwares, programas, plataformas, apps, para mantenernos conectados y comunicados, para realizar reuniones de trabajo -teletrabajo, home office-, clases virtuales, foros, videollamadas o

12 En la plataforma www.seguimoseducando.gob.ar de navegación gratuita desde todos los celulares, se encuentran disponibles diversos materiales y recursos para conocer, investigar y explorar sobre diferentes temas, problemas, fenómenos de la realidad, de la cultura, de la sociedad. Pretende ser un soporte a los esfuerzos colectivos para que la suspensión temporaria de las clases no implique una interrupción de las relaciones con los saberes.

13 Se encuentra disponible en la página oficial del Ministerio de Educación de La Pampa: https:// estudiar.lapampa.edu.ar/index.php/niveles/educacion-secundaria 
videoclases. Entre los que más se utilizan podemos mencionar Drive, ClassRoom, Edmodo, GoSchool, Meet, Zoom ${ }^{14}$, Hangouts, Campus Virtuales institucionales como Moodle, correos electrónicos, whatsapp, redes sociales como Facebook, Instagram para continuar con el proceso de enseñanza y de aprendizaje. Todos al mismo tiempo conectados a una red de internet. Si bien esta tecnología -producida y exportada desde países centrales-nos brinda la ventaja de acceder a la comunicación, creció nuestra participación pero también el poder de las grandes empresas. Sin embargo, la gran mayoría de los habitantes del planeta no tienen acceso a ellas, por lo que se deduce que su aislamiento es total. En Argentina, el Estado lanzó la plataforma Conferences para cubrir la demanda de teleconferencias durante el ASPO. Esta plataforma de videoconferencias se brindará a través de un servidor de proyecto de software libre Jitsi.org, un sistema similar al utilizado por Zoom (https://jitsi.dcarsat.com.ar/).

Este escenario educativo nos convoca al fortalecimiento de la responsabilidad política compartida por instituciones, docentes, familias mediante diálogos que permitan la construcción de acuerdos. En este sentido, Maggio (2020) plantea que los desafíos constituyen una trama multidimensional, cuyo rasgo central es la transformación en las formas de distribución del conocimiento. En tanto resulta imprescindible reconocer que en los entornos virtuales hay que otorgar un lugar de relevancia a la problematización, el co-diseño de las propuestas, la producción y creación de conocimiento.

Como docentes nos hemos reinventado en el marco de las transformaciones políticas, pedagógicas, curriculares, pero en esta oportunidad el sentido epistemológico de la inclusión de la tecnología implica además de los modos de construcción del conocimiento geográfico, el sentido social y cultural que tiene su inclusión. Hoy, la preocupación está en el acceso a los dispositivos y a las plataformas tecnológicas, y en la nueva configuración de las prácticas de la enseñanza, pero el post-coronavirus nos encontrará

14 Ante la demanda del teletrabajo y las comunicaciones via online familiares, la empresa Zoom Video Communications Inc."se ubica en una capitalización de mercado de 42,000 millones de dólares, lo que la hace más valiosa que su competidora estadounidense Slack, que registra un valor de 15,700 millones de dólares, e incluso, la pone por encima de plataformas globalmente conocidas como Twitter que posee un valor de 19,800 millones de dólares"(https:// www.iproup.com/innovacion/12556-zoom-el-gran-exito-en-tiempos-de-cuarentena-ya-valemas-que-twitter-y-slack) . El fundador, Eric Yuan, de origen chino llegó a Estados Unidos a inicios de la década de los 90, un momento de efervescencia tecnológica desde Silicon Valley en San Francisco, trabajó con la plataforma WebEx, en la que ascendió y, cuando esta se convirtió en Cisco, llegó a ser vicepresidente. En 2011 se fue de Cisco y empezó a trabajar en su Start-up. Hoy es considerado uno de los multimillonarios del Silicon Valley (https://www. eltiempo.com/tecnosfera/novedades-tecnologia/zoom-quien-es-el-multimillonario-fundadorde-plataforma-de-videollamadas-480754). 
con una escuela que promueva otras formas de enseñar y aprender. En relación con la Geografía, los modos aprender con el uso de las tecnologías ${ }^{15}$ propician nuevas maneras de sociabilidad, participación y de subjetivación, particularmente en lo referido a las modificaciones en las percepciones de espacio y tiempo.

\section{Claves para la enseñanza de la Geografía en el contexto de Pandemia}

En tiempos de Pandemia, la enseñanza de la Geografía posibilita el abordaje de los diferentes ejes temáticos y favorece la articulación de saberes, contenidos, conceptos y métodos de la disciplina en su trama pedagógica. En este sentido, las selección de Núcleos de Aprendizaje Prioritarios (NAP) de alcance nacional favorecerán los recortes temáticos que atiendan a la dimensión política de los territorios con categorías analíticas como: configuración de los territorios, fragmentación, integración, configuración del mapa político, organizaciones supranacionales, actores y movimientos sociales, conflictos y consensos, la dimensión socio-demográfica de los territorios con conceptos estructurantes como: desigualdad, vulnerabilidad, desempleo, pobreza, exclusión, marginalidad, segregación, cuestiones sanitarias, tecnológicas y educativas, la dimensión económica de los territorios con los conceptos clave como: la estructura, la dinámica y las problemáticas de los mercados de trabajo, las condiciones laborales, los sistemas financieros y la dimensión cultural de los territorios con conceptos clave como: redes, materiales e inmateriales, tecnocultura, culturas juveniles ${ }^{16}$, identidades, ciudadanía digital, Generación $X$, prácticas y las

15 Maggio (2020) analiza acerca de que las clases virtuales no nos deshumanicen y reconocer las prácticas culturales que nos seducen y llevarlas al aula. En el mismo sentido, Furman (2020) recupera ideas acerca del impacto de las tecnologías ante esta situación de Pandemia. Las autoras sostienen que "todos" estamos aprendiendo en comunidad de este escenario educativo que "no elegimos".

16 Un artículo publicado en el VII Congreso Nacional de Geografía de Universidades Públicas de Leduc, S.M, Nin, M.C. y Acosta, M. (2019) acerca de "Las series para pensar/crear/vivir escenarios educativos en contextos culturales juveniles" relacionan el impacto pedagógico de las series televisivas para su enseñanza en educación secundaria. Además, en un próximo trabajo se continuará con el análisis de películas que se encuentran en Netflix como Epidemia (1995), Contagio (2011), Virus (2013), 93 días (2016), Pandemia (2016), entre otras; las miniseries como The Hot Zone, que se estrenó en 2019 en National Geographic.

En el mismo sentido, un artículo sobre la importancia de las series televisas consideradas como consumos culturales privilegiados por adolescentes y jóvenes, de la Revista Cardinalis Núm. 9 (2017): $2^{\circ}$ semestre de Leduc, S.M. y Acosta, M. (2017) "Las series para pensar los sentidos de la educación, más allá de la pantalla". 
formas de participación, subjetividades. Los Derechos Humanos y la Educación Sexual Integral (ESI), resultan esenciales para pensar la enseñanza de modo transversal.

Pensar la enseñanza de esta problemática, implica un conjunto de claves para la comprensión que aportan los atributos de las sociedades como totalidades complejas, dinámicas y conflictivas y los territorios como la complejidad, la fragmentación, la desigualdad, entre otros, teniendo en cuenta las coordenadas de época, los dilemas éticos y políticos, las múltiples perspectivas y las contribuciones de diferentes disciplinas y campos de conocimiento (Gurevich, 2005).

Para iniciar este recorrido, la selección de conceptos ofrece un abanico de posibilidades para la enseñanza de temas y problemas que se re-significan en este contexto. Las múltiples desigualdades que se manifiestan en los territorios, nos implica como docentes a (re)situar sus significados y favorecer las articulaciones epistemológicas y didácticas en el marco de la pluralidad de opiniones, enfoques, criterios y pensamientos en la vida social, en los medios de comunicación, y en el mundo académico. De este modo, la desigualdad entendida como categoría de análisis nos permite interpretar las decisiones y los comportamientos de diferentes actores y/o sujetos individuales y colectivos que impactan en los territorios y configuran diversas territorialidades que entraman acciones a diferentes escalas espaciales y temporales.

Este virus que nos iguala, en tanto todos somos vulnerables, pone de manifiesto las desigualdades preexistentes en función de las condiciones sociales, culturales, económicas. En este sentido la Geografía desde finales del Siglo XX y principios del Siglo XXI a través de las investigaciones que estudian problemáticas territoriales a nivel global anticipan los desafíos de la enseñanza comprometida con la formación de ciudadanos críticos. Los tiempos y espacios pandémicos son las escalas temporales y espaciales de análisis geográfico que permiten evidenciar la crisis del sistema capitalista, en función de las decisiones políticas y económicas de los Estados más poderosos. Entre las reflexiones, es necesario reconocer las tensiones que suscita el aislamiento en el contexto de la interdependencia global, donde coexisten la esfera individual-familiar "microgeografías" y la esfera mundial en el que el virus traspone las fronteras de los territorios nacionales. Según Butler (2020) el virus no discrimina y nos ubica en igualdad respecto al riesgo de contraer la enfermedad. Al mismo tiempo, las amenazas por el fracaso de estados o regiones para organizar de manera anticipada las medidas sanitarias, el refuerzo de las políticas nacionales, el cierre de fronteras acompañada por manifestaciones de xenofobia y la llegada de 
emprendedores ávidos de capitalizar el sufrimiento global, todo esto asevera la velocidad con la cual la desigualdad radical -que incluye el nacionalismo, la supremacía blanca, la violencia contra las mujeres, migrantes, refugiados, pobres y la explotación capitalista encuentra formas de reproducirse y fortalecer sus poderes al interior de las zonas de Pandemia.

Los contenidos a enseñar son construcciones didácticas a partir de los conocimientos que otorgan sentido a los problemas de la realidad. Respecto a la situación de uno de los grupos más vulnerables ante esta enfermedad, se puede mencionar a los migrantes y refugiados que están en una situación de fragilidad mundial ante esta crisis humanitaria y de vulnerabilidad los derechos humanos. Según Nin y Lorda $(2019$, p. 139) “Concebir la educación desde la perspectiva de los derechos humanos es contemplar las dimensiones ética, cultural y política de éstos. Interpretarlos no solo como principios normativos que comparten los pueblos de diferentes latitudes, sino como una cultura de los derechos humanos". En este sentido, el mensaje de la Alta Comisionada de la ONU para los Derechos Humanos, Michelle Bachelet, y el líder de la Agencia de Refugiados, Filippo Grandi expresa que del modo en que la humanidad responda a esta crisis resultará el futuro de la misma, el trabajo en conjunto de las naciones y la atención de los más desfavorecidos es un desafío.

Muchas de estas mujeres, hombres y niños se encuentran en lugares donde los servicios de salud están sobrecargados o inaccesibles. Pueden estar confinados en campamentos y asentamientos, o vivir en barrios marginales urbanos, donde el hacinamiento y el saneamiento con pocos recursos aumentan el riesgo de exposición . (...) se necesita con urgencia apoyo internacional para ayudar a los países de acogida a intensificar los servicios, tanto para los migrantes como para las comunidades locales, e incluirlos en los acuerdos nacionales de vigilancia, prevención y respuesta. De lo contrario, se pondrá en peligro la salud de todos y se arriesgará a aumentar la hostilidad y el estigma (ONU 2020c).

Los aportes de la Geografía brindan marcos teóricos para comprender las decisiones actuales de las organizaciones mundiales, el rol de los estados, las intencionalidades e intereses de las industrias farmacéuticas, de las telecomunicaciones, la participación de los actores públicos y privados en las dinámicas territoriales. A partir de este entramado de relaciones conceptuales, se incorporan las dimensiones política y económica de los territorios con sus transformaciones recientes en el marco del sistema capitalista.

Esta problemática requiere de un abordaje integral y transversal que articule los ámbitos políticos y económicos, su estudio precisa de conceptos 
clave para su comprensión, entre ellos gobernanza resulta apropiado para interpretar el lugar de los sistemas institucionales y sus competencias para gestionar las políticas que respondan a las necesidades sociales y sanitarias. El término gobernanza, hace referencia a la gobernabilidad y designa el conjunto de procesos e instituciones que participan de la gestión política de una sociedad. De este modo, comprende el gobierno, las acciones de otros actores que juegan un rol en las orientaciones políticas estratégicas y en las opciones de política pública. Entre éstos se encuentran: actores políticos no gubernamentales que integran la sociedad civil, como empresas, sindicatos, asociaciones o actores individuales (Quintero, 2007). Al respecto Sassen (2000) expresa que la gobernanza es, en suma, un proceso por el cual el gobierno y la sociedad interactúan en pos de sus intereses comunes. En esta estrategia se ponen en juego la participación del gobierno y del sector privado, es decir el campo empresarial y la sociedad civil, especialmente las organizaciones no gubernamentales, en la toma de decisiones y diseños de políticas públicas. La gobernanza está ligada al concepto de red y de interacción entre personas y grupos. En este sentido los actores que interaccionan, con diferente nivel y poder de decisiones se pueden identificar según sus escala de intervención.

A escala global, la ONU como Organismo Internacional nuclea casi la totalidad de los países del mundo a través de la Autoridad directiva y Coordinadora de la acción sanitaria, la OMS, está liderando las recomendaciones y acciones sanitarias frente a esta pandemia. Desde esta Organización se reconoce la fragilidad de los sistemas sanitarios de la mayoría de los países del mundo, sin embargo sus directricespara planificar las estrategias de acción frente al COVID-19 expresan la necesidad de continuar prestando servicios sanitarios y esenciales y mitigar el colapso del sistema (OMS, 2020). Para ello los Estados tienen que reorganizar sus sistemas sanitarios a escala nacional, regional y local para que en todo el territorio los ciudadanos tengan acceso a la atención médica correspondiente. Se podría afirmar que se activanlas propuestas de los Objetivos de Desarrollo Sostenible ${ }^{17}$, es decir que el compromiso firmado por los Estados respecto a su cumplimiento se impulsa ante la emergencia de esta pandemia.

Como se puede observar en lo que transcurre este período de la Pandemia, la Organización Mundial de la Salud lidera las recomendaciones y los Estados observan y aprenden de las decisiones que otros toman. Sin

17 En relación a los Objetivos de Desarrollo Sostenible y su vínculo con el concepto de Gobernanza se puede consultar nuestro análisis previo en: María Cristina Nin y Stella Maris Shmite (2019.) "Objetivos de desarrollo sostenible. Desafíos de la Universidad ante la Agenda $2030 "$. 
embargo, esta crisis desnuda la imposibilidad de los Estados de poder efectivizar el compromiso acordado en los ODS y la enorme brecha -entre las que se encuentra la brecha digital- que existe a escala mundial y regional. Por otra parte se ponen en duda los mecanismos de formación de alianzas mundiales, tal como se propone en el Objetivo 17. Además, la ciudadanía a nivel mundial a través de la información que circula, conoce las extremas carencias en relación a la persistencia de la pobreza, el hambre, la falta de agua potable y la malnutrición, en territorios lejanos y también a escala local. Por lo tanto, garantizar una vida sana y promover el bienestar para todos, promover y garantizar una educación inclusiva, equitativa y de calidad para lograr la igualdad de género y autonomía de las mujeres, niños/as y sujetos vulnerables, es un desafío de la comunidad internacional.

En escalas regionales o locales, las decisiones políticas de los Estados respecto a las estrategias a implementar en esta crisis sanitaria, muestran las desigualdades en las decisiones y la profunda inequidad al interior de sus sociedades. Estados que deciden: rápidamente aislar a la población para evitar la propagación, que aplican tecnologías para geolocalizar a infectados y así disminuir los contagios, inversiones en investigación para avanzar con la creación de la vacuna ${ }^{18}$, Estados que niegan la problemática y priorizan la economía, estados que construyen hospitales y compran insumos y los que construyen cementerios o los improvisan. Sin dudas las desigualdades persistentes entre las diferentes regiones del mundo se visibilizan ante esta crisis global. América Latina considerada la región más desigual. Los países africanos, si bien recibieron tardíamente la propagación del virus, presentan los sistemas de salud más débiles del planeta. Sin embargo los expertos afirman que la ventaja que tienen estos Estados, especialmente los de África subsahariana es la experiencia por haber atravesado las crisis sanitarias anteriores, tales como la del ébola ${ }^{19}$ (Naranjo, 2020).

La perspectiva sociológica de Boaventura de Sousa Santos (2020) aporta dos miradas analíticas en relación con la crisis. Por un lado, la crisis actual como transitoria por los factores que la ocasionan y por otro, la crisis permanente cuando es la causa que explica todo lo demás. Las consecuencias serán positivas y negativas según las dimensiones de análisis de la problemática, la desaceleración de la actividad económica, especialmente en

18 Una noticia del "Diario El País" del 26/03/2020 señala que "La industria farmacéutica ya ensaya con pacientes 20 vacunas y 30 tratamientos contra el Covid-19, aunque los laboratorios no creen que la primera vacuna llegue antes de 12 a 18 meses". Allí, se juegan intereses y estrategias de las industrias farmacéuticas en desarrollar la vacuna y entrar al mercado de la competitividad.

19 En un trabajo previo se analizó la crisis del ébola en Africa occidental, Nin y Shmite (2016). Vulnerabilidad Multidimensional En África Occidental: El Ébola Como Problemática Territorial. 
Estados Unidos ${ }^{20}$ y China, tiene obvias consecuencias negativas ${ }^{21}$ y al mismo tiempo tiene algunas consecuencias positivas en cuanto a la situación económica ${ }^{22}$ o como la disminución de la contaminación atmosférica. Asimismo, en los territorios se hacen visibles las ausencias y las fragilidades de un mundo entero que cambia las reglas del juego en el funcionamiento del sistema capitalista.

Respecto a la perspectiva ambiental ${ }^{23}$, durante estos últimos días se comenzaron a realizar estudios acerca de las emisiones globales de dióxido de carbono CO2 sobre todo en China, aunque también en otros países, y se comprobaron reducciones a partir de marzo, lo que permite hablar de un respiro a la naturaleza. El entramado de dimensiones de análisis que conlleva la aparición del coronavirus incluye las cuestiones ambientales ${ }^{24}$ que se relacionan con el alcance de las desigualdades sociales y la tendencia a la concentración de la riqueza como producto del capitalismo neoliberal. La expansión de las fronteras de explotación facilita la circulación del virus a escala global. Entre los discursos ambientales respecto a esta problemática, en América Latina, las luchas ecoterritoriales proponen otras relaciones sociales, que cuestionan la actual destrucción de la naturaleza y los ecosistemas ${ }^{25}$, que incluyen desde los derechos de la naturaleza a la

20 Una noticia de "Página 12" del día 10/04/2020 anuncia que "Estados Unidos: el desempleo llegó a niveles históricos por el coronavirus", 16,6 millones de personas pidieron el subsidio por desempleo.

21 El periódico "The Conversation" del 02/03/2020 hace referencia al creciente impacto del coronavirus en la economía mundial. El complejo de cinco fábricas de Hyunday en Ulsan, Corea del Sur, con capacidad para fabricar 1,4 millones de vehículos al año, quedó en silencio el 7 de febrero debido a la falta de piezas como consecuencia del brote de coronavirus.

22 El "Diario El Cronista" del 27/03/2020 analiza cómo cinco empresas chinas lograron crecer en el medio de la Pandemia.

23 Para ampliar lecturas acerca de la cuestión ambiental, se puede consultar (ONU, 2020 d) acerca de "La cuarentena por el coronavirus mejora la calidad del aire, pero no sustituye la acción climática" (23/03/2020) y "La pandemia de coronavirus es una oportunidad para construir una economía que preserve la salud del planeta” (ONU e, publicado el 7/04/2020).

24 Leandro del Moral (2020) explica la relación del Covid-19 con el concepto de sociedad el riesgo, en su análisis discute los riesgos modernos enrelación con la dualidad naturaleza/ cultura, el rol de la ciencia y los expertos, la relación de los desastres con las desigualdades ociales y el surgimeinto de nuevos roles geopolíticos.

25 Shah (2020) analiza "Contra las pandemias y la ecología". El ébola es un buen ejemplo de esto. Un estudio llevado a cabo en 2017 desveló que era más frecuente que este virus, cuyo origen ha sido localizado en varias especies de murciélago, apareciera en zonas de África Central y Occidental que han sufrido deforestaciones recientemente. Cuando talamos los bosques, obligamos a los murciélagos a posarse en los árboles de nuestros jardines y nuestras granjas. Es fácil imaginar qué es lo que ocurre a continuación: un humano ingiere saliva de murciélago al morder una fruta cubierta de microbios; o bien, al intentar cazar y matar a este visitante inoportuno se expone a los microbios que han encontrado refugio en sus tejidos. Así es como 
ética del cuidado como un problema que nos incumbe como humanidad (Svampa, 2020a).

\section{El camino reflexivo recién inicia}

Estas reflexiones constituyen un lugar de encuentro de múltiples voces que interpretan la pandemia desde sus territorios, mediados por sus posturas políticas, sociales y económicas, en este sentido nuestra intención de ponerlos en diálogo y debate evidencia la diversidad de interpretaciones sobre la problemática. De tal modo, que la comprensión geográfica implica el análisis, la comparación, la definición, la relación de lo producido para experimentar el pensamiento crítico respecto a las contribuciones brindadas por sujetos individuales y colectivos en diferentes escalas, contextos, territorios.

Como nunca antes en la historia de la humanidad, ante esta problemática, la ciudadanía se implicó y comprometió en la participación y cumplimiento de las decisiones estatales. Las estructuras económicas, sociales e institucionales están cuestionadas por el modo en que gestiona la presente crisis. Los territorios se convierten en ámbito de actuación de las políticas públicas, las cuales construyen cartografías variadas de acuerdo a las estrategias adaptadas a sus respectivas realidades. El contexto actual nos hace recordar que el orden institucional actual no es privado completamente, la normatividad vigente comparte agentes estratégicos que pertenecen al sector privado, pero también al público. Sin embargo, el dilema entre la resolución individual y colectiva de la presente catástrofe delineará un futuro en el que se acentuarán las individualidades o se optará por las decisiones comunitarias.

Ante el riesgo de circulación del virus y el veloz contagio, gran parte de la población mundial está confinada en sus hogares. La protección de la salud de los ciudadanos se realiza a expensas del aislamiento y el distanciamiento social. Algunos autores consideran a este estado de excepción aplicado tanto en estados autoritarios como en democracias como un nuevo régimen biopolítico (Espósito, 2020) o estado de excepción transitorio por vía de los estados nacionales (Svampa, 2020 b). Sin dudas la paradoja

multitud de virus portados por los murciélagos, inofensivos para ellos, consiguen penetrar en la población humana -podemos citar el ébola como ejemplo, pero también es el caso del virus de nipah (presente principalmente en Malasia y Bangladesh) o del marburgvirus (sobre todo en África Oriental). Este fenómeno se denomina "salto de virus entre especies". Aunque sea infrecuente, puede hacer que virus procedentes de animales se adapten a nuestros organismos y evolucionen hasta convertirse en patógenos. 
que representa evitar el colapso sanitario a través del control y vigilancia riguroso de la población puede brindarnos una oportunidad de (re)pensar el sistema capitalista en decadencia y hacer foco en la ética de la vida y la política del servicio para una nueva etapa de la humanidad (Dussel, 2020 b).

La escala local es el mejor ámbito para el desarrollo de la gobernanza, con una finalidad concreta de desarrollo o con un enfoque político que atiende a las propias realidades socioterritoriales. Sin embargo, la articulación de las decisiones a escala local, regional, nacional y mundial, es sumamente necesaria para construir una gobernanza global que responda a valores democráticos, al pleno cumplimiento de los derechos sociales y humanos por y para una ciudadanía activa. Construir agendas de prioridades en las que se articulen las necesidades locales con el diálogo a nivel global en lo que utópicamente podría denominarse, como una nueva geopolítica de la solidaridad.

La historia distópica en la que se observan escenarios deshumanizados, ya no es parte de un cuento de ciencia ficción, ¿estaremos preparados para evitar la cruedad, las injusticias y la pérdida de derechos civiles? El desafío es aprender a ser ciudadanos/as conscientes de que lo desconocido se avizora y requiere de pensar nuevas estrategias para hacer y diseñar políticas basadas en la solidaridad, el compromiso, el cuidado y respeto del otro hacia la búsqueda del bien común.

\section{Referencias bibliográficas}

Aizen, M. (2020). Las nuevas pandemias del Planeta devastado. Revista Anfibia. Recuperado de: https://revistaanfibia.com/cronica/lasnuevas-pandemias-del-planeta

Agamben, G. (2020, 5 de marzo). La invención de una epidemia. Diario Pagina 12. Recuperado de: https://www.pagina12.com.ar/250990-lainvencion-de-una-epidemia

Alba Rico, S. y Herrero Y. (2020). ¿Estamos en guerra?. CTXT. 22/3/20. № 258, marzo 2020. Recuperado de: https:/ctxt.es/es/20200302/ Firmas/31465/catastrofe-coronavirus-guerracuidados-ciudadanos-ejercito-alba-rico-yayo-herrero.htm?fbclid=IwAR2gPh1DSjoJY Qe87p72Cs9QzfH0B7BXAwNVjwQX8T53 OZ1ICk9WANL21kA

Argentina.gob.ar (2020, 7 de abril). El ANLISMalbrán logró secuenciar el genoma comple- to del nuevo coronavirus SARS-COV-2. Recuperado de: https://www.argentina.gob.ar/ noticias/el-anlis-malbran-logro-secuenciarel-genoma-completo-del-nuevo-coronavirussars-cov-2

Butler, J. (2020, 20 de marzo). El capitalismo tiene sus límites. Revista Intersecciones. Traducción de Claudia Bacci y Roberto Pittaluga. Recuperado de: https://www.intersecciones. com.ar/2020/03/20/el-capitalismo-tiene-suslimites/

Chomsky, N. (2020). Es el momento de enseñanzar a los niños a entender el mundo. Aprendemos Juntos. Diario El País. 1/4/2020. Recuperado de: https://aprendemosjuntos. elpais.com/especial/es-el-momento-deensenar-a-los-ninos-a-entender-el-mundonoam-chomsky/?fbclid=IwAR0C_Ti8WE6- 
MLeds4vWnG86Qr6iS1WB6iSERDkEYhvztHhoMDxFUWtmWKtI

De Souza Santos, B. (2020, 21 de marzo). Coronavirus: todo lo sólido se desvanece en el aire. Recuperado de: https://mamvas.blogspot. com/2020/03/coronavirus-todo-lo-solido-sedesvanece.html?fbclid=IwAR0b8tUD0h9OI 9giP0kI1XvwS8ZOxMiOQTtHClrzfcx6Qbzqlrbm1aYSpss

Del Moral, L. (2020). Covid-19: profundizando En La Cambiante Sociedad del Riesgo Global. $A G E$. Recuperado de: https://www.age-geografia.es/site/wp-content/uploads/2020/04/ leandro-del-moral-v1.pdf.

Diario El País. (2020, 26 de marzo). La industria farmacéutica ya ensaya con pacientes 20 vacunas y 30 tratamientos contra el Covid-19. Recuperado de: https://cincodias.elpais.com/cincodias/2020/03/26/ companias/1585220679_850148.html

Diario Página 12. (2020, 10 de abril). Estados Unidos: el desempleo llegó a niveles históricos por el coronavirus. Recuperado de:https://www. pagina12.com.ar/258572-estados-unidos-eldesempleo-llego-a-niveles-historicos-por-e

Diario El Cronista. (2020, 27 de marzo). Coronavirus: cinco empresas chinas lograron crecer en medio de la pandemia. Recuperado de: https://www.cronista.com/apertura-negocio/ empresas/Coronavirus-cinco-empresas-chinas-lograron-crecer-en-medio-de-la-pandemia--20200326-0004.html

Diario The Conversation. (2020, 2 de marzo). Academic rigor, journalista flair. El creciente impacto del coronavirus en la encomía mundial. Recuperado de: https://theconversation. com/el-creciente-impacto-del-coronavirusen-la-economia-mundial-132745

Diario La Vanguardia. (2020, 4 de marzo). Habermas: nunca habíamos sabido tanto de nuestra ignorancia. 04/04/2020Recuperado de: https://www.lavanguardia.com/ cultura/20200404/48295927411/habermasnunca-habiamos-sabido-tanto-de-nuestraignorancia.html

Dillon, B. (2020). Coronavirus: Geografía y Turismo. Revista Contexto Universitario. Recuperado de: http://contexto.unlpam.edu.ar/index. php/articulos/analisis/33-coronavirus-geografia-y-turismo?fbclid=IwAR0p-VZaWuODckhIKO3qw1 paoopEBkUSZ3ayKrUhp_ xQgdvQyZzHPMgNqnY\#.XnUm4RMYz71. facebook
Duer, P. (2020, 6 de abril). Harari: "En el largo plazo, la peor de las crisis se sufrirá en los países pobres". Diario El Pais. Recuperado de: https://elpais.com/elpais/2020/04/06/planeta futuro/1586170713 492779.html?fbcli d=IwAR0sCLISgoDvYBW4Fgi4p1NdQdB0 cYAeb_rJURTowHNnphDBAul63wsjFyU

Dussel, E. (2020a). Dussel reflexiona sobre la epidemia: la humanidad cambia de objetivos o se hará el harakiri. 2/4/2020. En Aristegui Noticias. 35,57 Min. Recuperado de; https:// www.youtube.com $/$ watch? $v=Z j M a Y o 1 \mathrm{cmD}$ Q\&feature=youtu.be\&fbclid=IwAR 1 iwbSU 9yhaHnxsJkSJaVhdgwnegxoBsbblMdQzxG VXrchC99deiwWWQeg

Dussel, E. (2020b). 2020: La Pandemia con Enrique Dussel. Ética y política. 9/4/20. Recuperado de: https://www.youtube.com/watch $? \mathrm{v}=$ ILuu31YWFAg $\&$ feature $=$ share $\&$ fbclid $=$ IwAR3atCxfw_-W6XHrWo4tU9bB9L4fL eS0iwenfJEeEJÜHHIeEf_v5Agdxk

Espósito, R. (2020, 24 de marzo). Biopolítica y coronavirus. Recuperado de: https://www. filco.es/biopolitica-y-coronavirus/?fbclid=Iw AR2GReJbEy5F1I2fDhvKSQoqS78am9IgJf GlGuI0X3Zhg10EvGbpy-8_RDM

Fletcher, R., Murray, I., Blázquez, M. y Banco, A. (2020). Turismo, decrecimiento y la crisis del COVID-19. 24/3/20. Recuperado de: http:// www.albasud.org/blog/es/1196/turismo-decrecimiento-y-la-crisis-del-covid-19

Giorgi, G. y Rodríguez, F. (compiladores) (2007). Ensayos sobre biopolítica Excesos de vida. Buenos Aires: Paidós. Espacios del Saber.

Foucault, M. (2006). Seguridad, territorio, población. Buenos Aires. Fondo de Cultura económica.

Furman, M. (2020). Nuevas formas de aprender y enseñar a partir de la Pandemia. TEDxRiodeLaPlata. Recuperado de: https://www.youtube.com $/$ watch? $\mathrm{v}=\mathrm{Tgr} 0 \mathrm{mfEYhUs} \&$ feature $=\mathrm{y}$ outu.be

Gurevich, R. (2005). Sociedades y territorios en tiempos contemporáneos. Una introducción a la enseñanza de la geografía. Buenos Aires: Fondo de Cultura Económica.

Han, B-Ch. (2020, 22 de marzo). La emergencia viral y el mundo de mañana. Byung-Chul Han, el filósofo surcoreano que piensa desde Berlín. Diario El País. Recuperado de: https://elpais.com/ideas/2020-03-21/la-emergencia-viral-y-el-mundo-de-manana-byung- 
chul-han-el-filosofo-surcoreano-que-piensadesde-berlin.html

Harvey, D. (2020, 20 de marzo). Anti-Capitalist Politics in the Time of COVID-19. 20/3/20. Jacobin. Recuperado de: https://jacobinmag. com/2020/03/david-harvey-coronaviruspolitical-economy-disruptions. Taducido: https://www.laizquierdadiario.com/Politicaanticapitalista-en-la-epoca-de-COVID-19

Kliksberg, B. (2005). "Hacia un nuevo perfil del Estado en América Latina: los cambios en las percepciones y las demandas de la ciudadanía”. Revista CLAD Reforma y Democracia $\mathrm{N}^{\circ} 32$, Caracas.

Lander, E. (ed). (2000). La colonialidad del saber: eurocentrismo y ciencias sociales. Perspectivas latinoamericanas. Buenos Aires: CLACSO. Recuperado de: https://www.tni. org/files/download/La\%20colonialidad $\% 20$ del $\% 20$ saber. $\% 20$ Eurocentrismo $\% 20 y \% 20$ ciencias $\% 20$ sociales.pdf

Leduc, S.M., Nin, M.C. y Acosta, M. (2019). Las series para pensar/crear/vivir escenarios educativos en contextos culturales juveniles. $\mathrm{Pu}-$ blicado en el VII Congreso Nacional de Geografía de Universidades Públicas. Recuperado de: http://jornadasgeografia.fahce.unlp. edu.ar/front-page/actas/ponencias/Leduc.pdf

Leduc, S.M. y Acosta, M. (2017) Las series para pensar los sentidos de la educación, más allá de la pantalla. Revista Cardinalis Núm. 9 (2017): $2^{\circ}$ semestre. Recuperado de: https:// revistas.unc.edu.ar/index.php/cardi/article/ view/18945

Lois, C. (2018). Terrae incongnitae. Modos de pensar y mapear geografias desconocidas. Buenos Aires: Eudeba.

Lois González, R. (2020). Geografía (Periodística) de la crisis del Coronavirus. $A G E$. Recuperado de: https://www.age-geografia.es/ site/wp-content/uploads/2020/03/generandodiscurso-2.pdf.

Maggio, M. (2020). Clases virtuales: el desafío es que las plataformas no nos deshumanicen. RED/ACCIÓN. Recuperado de: https:// www.redaccion.com.ar/clases-virtuales-eldesafio-es-que-lasplataformas-no-nos-deshumanicen/

Marcu, S. (2020). La crisis del Coronavirus En el Contexto Europeo. Reflexiones Geopolíticas. $A G E$. Recuperado de: https:/www.age-geografia.es/site/wp-content/uploads/2020/03/ generando-discurso-3.pdf
Médicos sin Fronteras. (2020). ¿Qué es una pandemia? ¿Cuál es la diferencia entre pandemia y epidemia?. Fecha: 12.03.2020. Recuperado de: https://www.msf.org.ar/actualidad/queuna-pandemiacual-la-diferencia-pandemiay-epidemia

Méndez, R. (2020). Reflexiones sobre la crisis del COVID-19. Sitiados por el Coronavirus: Consideraciones de un geógrafo. $A G E$. Recuperado de: https://www.age-geografia.es/site/ wp-content/uploads/2020/03/mendez-v1.pdf

Mora Aliseda, J. (2020) Pandemia, Pobreza y Población (P.P.P.) Una Espiral Viral. $A G E$. Recuperado de: https://www.age-geografia. es/site/wp-content/uploads/2020/03/crisiscoronavirus-Jmora-v2.pdf

Naranjo, (2020, 29 de marzo). Äfrica: el arma de la experiencia frente a la falta de recursos. Recuperado de: https://elpais.com/internacional/202003-28/africa-el-arma-de-la-experiencia-frentea-la-falta-de-recursos.html

Nin, M.C. y Lorda, M. A (2019). Educación geográfica y formación en ciudadanía desde la perspectiva de los derechos humanos. Cardinalis. Revista del Departamento de Geografía. FFyH -UNC-Argentina. ISSN 2346-8734Año 7. $\mathrm{N}^{\circ} 132 \quad-2^{\circ}$ semestre 2019. Pp.136-153. Recuperado de: https:// revistas.unc.edu.ar/index.php/cardi/article/ view/27149/28809

Nin, M. C. y Smithe, S. M. (2019). Objetivos de desarrollo sostenible. Desafíos de la Universidad ante la Agenda 2030. Disponible en: Repensar las Geografías para construir saberes en contextos dinámicos. (2019). Beatriz Dillon, María Cristina Nin y Daila Pombo (Compiladoras). Santa Rosa: EdUNLPam. Libro digital, EPUB. Archivo Digital: descarga y online. ISBN 978-950-863-389-7

Nin, M. C. y Shmite, S. M. (2016). Vulnerabilidad multidimensional en África Occidental: El ébola como problemática territorial. Contra Relados desde el Sur. No 13. 2016. Pp.73-88. Recuperado de: https://revistas.unc.edu.ar/index.php/contra-relatos/issue/view/1306

Oliva Cañizares, A. (2020). La crisis sanitaria del coronavirus (covid19): análisis, tendencias y propuestas. pp.1-5. $A G E$. Recuperado de: https://www.age-geografia.es/site/wp-content/uploads/2020/03/antonio-oliva-v1.pdf

OMS. (2020). La OMS publica directrices para ayudar a los países a mantener los servicios sanitarios esenciales durante la pande- 
mia de COVID-19. 30/3/2020. Recuperado de: https://www.who.int/es/news-room/ detail/30-03-2020-who-releases-guidelinesto-help-countries-maintain-essential-healthservices-during-the-covid-19-pandemic

ONU. (2020a). El coronavirus COVID-19 es una pandemia. 11/3/2020. ONU Noticias. Recuperado de: https://news.un.org/es/ story/2020/03/1470991

ONU. (2020b). Mientras China le está ganando la batalla al coronavirus, el resto del mundo no está preparado. 25/2/2020. ONU Noticias. Recuperado de: https://news.un.org/es/ story/2020/02/1470141

ONU. (2020c). La pandemia de coronavirus es una prueba para nuestros sistemas, valores y humanidad. 13/03/2020. ONU Noticias. Recuperado de: https://news.un.org/es/ story/2020/03/1471141

ONU. (2020d). La cuarentena por el coronavirus mejora la calidad del aire, pero no sustituye la acción climática. 23/03/2020. Recuperado de: https://news.un.org/es/ story/2020/03/1471562

ONU. (2020e). La pandemia de coronavirus es una oportunidad para construir una economía que preserve la salud del planeta. 07/04/202. Recuperado de: https://news.un.org/es/ story/2020/04/1472482

Prieto Flores, M. E. (2020, 8 de abril). Microgeografías de la pandemia en la vejez. En Envejecimiento en Red. Recuperado de: http:// envejecimientoenred.es/microgeografias-dela-pandemia-en-la-vejez/

Quijano, A. (2014). Colonialidad del poder, eurocentrismo y América Latina. En: Cuestiones $y$ horizontes : de la dependencia históricoestructural a la colonialidad/descolonialidad del poder. Pp.737-832. Buenos Aires : CLACSO.

Quintero, S. (2007). "Territorio, gobierno y gestión: temas y conceptos de la nueva geografía política”. En Fernández Caso, M. Victoria y Gurevich, Raquel (coord) (2007). Geografia. Nuevos temas, Nuevas Preguntas. Un temario para su enseñanza. Buenos Aires: Biblos.

Real Academia Española (RAE). (2020). Epidemia. rae.es. Recuperado de: https://dle.rae. es/?w=epidemia

Real Academia Española (RAE). (2020). Pandemia. rae.es. Recuperado de: https://dle.rae. es/?w=pandemia
Rodríguez Rodriguez, V. (2020). Covid19 y Las Personas (Mayores) En El Análisis Geo-Demográfico (I). $A G E$. Recuperado de: https:// www.age-geografia.es/site/wp-content/ uploads/2020/03/vicente-rodriguez-v1.pdf

Rodríguez Rodriguez, V. (2020). Covid-19 y Las Personas (Mayores): Los Entornos Geográficos y Sociales (II). $A G E$. Recuperado de: https://www.age-geografia.es/site/wp-content/uploads/2020/03/vicente-rodriguez-v2. pdf

Sassen, S. (2000). "Nueva Geografía Política. Un nuevo campo transfronterizo para actores públicos y privados". Conferencia del Millenium, London School of Economics, 25 de enero de 2000. (http://www.sindominio. net/arkitzean/multitudes/multitudes3/nueva geografia_política.htm; traducción de Beñat Baltza.

Schulz, S. (2020). La geopolítica del COVID-19. Espartaco Revista. Recuperado de: https:// espartacorevista.com/2020/03/la-geopoliticadel-covid-19/

Shah, S. (2020). Contra las pandemias, la ecología. Le Monde diplomatique en Español. Marzo 2020. Recuperado de: https://mondiplo.com/ contra-las-pandemias-la-ecologia

Soria Noticias. (2020, 4 de abril). Los geógrafos de CyL demuestran que la cuarentena funciona. Recuperado de: https://sorianoticias.com/ noticia/2020-04-04-los-geografos-cyl-venque-cuarantena-funciona-66781

Svampa, M. (2020a , 5 de abril). Estamos en una crisis sistémica donde el horizonte civilizatorio está en disputa. Telam. Recuperado de: https://www.noticiasde.com.ar/sociedad/ svampa-estamos-en-una-crisis-sistemicadonde-el-horizonte-civilizatorio-esta-endisputa-111125

Svampa, M. (2020b). Reflexiones para un mundo post-coronavirus. Nueva Sociedad. Abril 2020. Recuperado de: https://www.nuso.org/ articulo/reflexiones-para-un-mundo-postcoronavirus/

Svampa, M. y otros. (2020). La Fiebre. Editorial ASPO. Recuperado de: https://drive. google.com/file/d/1 k-YzHu9LgPajOuqz8WS5XKjfbj-EqAvM/view

Tobío, O. (2020, 24 de marzo). Geografía. Un arma de terror televisivo. Diario Página 12. Recuperado de: https:/www.pagina12.com. ar/254894-geografia-un-arma-de-terror-televisivo 
Zizek, S. (2020, 7 de abril). La Barbarie con rostro humano. En Conversación sobre la historia. Recuperado de https://conversacionsobrehistoria.info/2020/04/07/la-barbarie-con-rostrohumano/?fbclid=IwAR1 wo 7do7dYJLyUoM gRn8wzEK6_IW8tYDCdoPxBPfphATYsH qYI_cCD9Qs 